\title{
Caveolar Disruption with Methyl- $\beta$-Cyclodextrin Causes Endothelium-Dependent Contractions in Wistar Rat Carotid Arteries
}

Ashraf Albrakati ( $\square$ mchakl@hotmail.com )

Taif University College of Medicine https://orcid.org/0000-0002-4116-7865

\section{Research Article}

Keywords: Caveolae, carotid artery, maxi-K channels, contractions, nitric oxide

Posted Date: January 27th, 2022

DOI: https://doi.org/10.21203/rs.3.rs-1236015/v1

License: (c) (i) This work is licensed under a Creative Commons Attribution 4.0 International License.

Read Full License 


\section{Abstract}

Caveolae are organizing centers for cellular signal transduction in endothelial cells (ED) and smooth muscle cells (SMCs) in the blood vessels.

Methods: Myography was used to investigate effects of caveolar disruption using methyl- $\beta$-cyclodextrin (MBCD) on maxi-K channels in rat carotid arteries.

Results: Incubation of carotid segments with MBCD augmented contractions in response to BaK (chemical channel agonist) but not those induced by depolarizing high potassium physiological saline (KPSS). In contrast, incubation with cholesterol-saturated MBCD (Ch-MBCD) abolished the effects of MBCD. Mechanical removal of endothelial cells by MBCD triggered a small contraction in response to BaK. Incubation with nitroarginine methyl ester (L-NAME) inhibited nitric oxide (NO) release, thereby causing increased contractions in response to $\mathrm{BaK}$, and this effect was reversed by pretreatment with $M B C D$. These results suggest that MBCD inhibits endothelial NO release. Contrastingly, inhibition of maxi$\mathrm{K}$ channels with iberiotoxin enhanced contractions in response to BaK. Likewise, L-NAME decreased the contractile effect of iberiotoxin, as in the ED-denuded arteries. Transmission electron microscopy (TEM) showed the presence and absence of caveolae in intact blood vessels before and after MBCD treatment, respectively, whereas histology confirmed ED removal after the treatment.

Conclusions: Caveolar disrupted using MBCD impairs ED-dependent relaxation by inhibiting the release of NO from the ED and altered the contractility of SMCs independent of the ED due to reduced contribution of maxi-K channels to the SMC membrane potential, causing depolarization and increasing carotid artery contraction. These findings might help to understand physiological role of the maxi-K channels in rat carotid arteries.

\section{Introduction}

The brain is among the most metabolically active organs and hence has high energy and blood supply demands (Berg et al. 2002), predisposing it to ischemic injury. Excessive blood flow in the brain that exceeds the metabolic needs may cause the breakdown of the blood-brain barrier and transudation into the pericapillary astrocytes and interstitium (Nakada \&Kwee 2019). Carotid vasculature is highly sensitive to changes in the carbon dioxide partial pressure; carbon dioxide has a significant vasodilatory role in the carotid vasculature, increasing the blood flow to the brain (Bosmia et al. 2015, Sato et al. 2012). High partial pressure of carbon dioxide suppresses carotid activity. A common property of most carotid arteries is a highly selective and specialized blood-brain barrier (Andjelkovic et al. 2020, Wong et al. 2013). In the systemic circulation, the regulation of blood pressure is primarily mediated by the vascular smooth muscle cell contractile state in the walls of the resistance vessels (Touyz et al. 2018). In relation to the hemodynamic regulation of the microvasculature, the cellular processes linking the myogenic.

Carotid blood pressure is maintained by an autoregulatory mechanism that maintains a stable carotid blood flow despite fluctuating systemic arterial pressures (Shekhar et al. 2017). Carotid autoregulation 
occurs via various mechanisms, including autonomic, metabolic, and myogenic mechanisms (Ghosh et al. 2015). Myogenic tone protects peripheral vessels such as carotid arteries from damage induced by pressure and regulates blood pressure (Miyagi et al. 1996). The myogenic tone and carotid autoregulation are under the control of the autonomic nervous system and several vasoactive factors such as EDHF and NO, and are dependent on calcium influx via voltage-gated channels such as L- and Ttype calcium channels (Miyagi et al. 1996). However, the mechanisms of vascular smooth muscle constriction remain unclear.

Caveolae are described as flask-shaped microdomains of membranes rich in glycosphingolipids and cholesterol (Bender et al. 2002). Caveolae mainly consist of caveolin-1, caveolin-2, and caveolin-3, and are characterized by high cholesterol and sphingolipid content (Cohen et al. 2004, Rothberg et al. 1992). Caveolin-1 is essential and sufficient for caveolar formation (Drab et al. 2001), while caveolin -2 is mostly co-expressed with caveolin-1 to form hetero-oligomeric complexes. Caveolin-2 seems to have a supporting role in caveolar formation (Sowa et al. 2001). Caveolin-3, which is mainly expressed in muscle cells, has an analogous role to caveolin-1 in non-muscle cells (Cohen et al. 2004). However, all three caveolin isoforms express vascular SMCs (Al-Brakati et al. 2015, Cohen et al. 2004). They play a role in several physiological processes such as cellular signaling, lipid uptake, and pathophysiologic events in blood vessels and heart (Gu et al. 2017). In the maintenance of homeostasis, the caveolae serve as signal platforms for molecules such as nitric oxide synthase in the vascular ED (Sowa et al. 2001). Nevertheless, a large number of receptors and signaling molecules present on endothelial cells are also numerous in the caveolae. Examples include G-proteins, endothelial nitric oxide synthase (eNOS), Maxi-K ${ }^{+}$channels, Ttype channels, and protein kinase $\mathrm{C}$ (PKC) and $\mathrm{A}$ (PKA). These receptors and signaling molecules bind to and are inhibited by caveolin-1 (Fridolfsson et al. 2014, Zundel et al. 2000). eNOS is particularly important in the pathogenesis of hypertension due to its role in the regulation of blood pressure and homeostasis in the cardiovascular system. In relation to eNOS, the caveolae of endothelial cells regulate its activation via caveolin-1 (Chen et al. 2018).

Caveolin-1 deficiencies or loss of function mutations have been shown to result in arterial relaxation induced by acetylcholine and a chronic elevation of NO levels. Even though these would be expected to decrease the blood pressure, several studies have reported elevated systolic blood pressure and increased heart rate in cases of chronic caveolin-1 loss and subsequent eNOS hyperactivation, possibly due to prolonged activation of the baroreceptor reflex, which results in increased neurogenic tone and sympathetic stimulation. (Lian et al. 2019a). Caveolin-1 deletions have been shown to interfere with the localization and activity of L-type calcium channels, thereby increasing the myogenic tone (Toselli et al. 2005). This increases vascular resistance and may result in hypertension. In some medium-sized arteries, the maxi-K channels located within caveolae regulate the myogenic tone, they regulate the L-type channels, which may indicate their association or synergistic action in blood pressure regulation (Lian et al. 2019b).

In several studies, the disruption of caveolae using MBCD has been implicated in hypercontractility in different arteries. In addition, disrupted caveolae lead to loss of function mutations and/or contribute to 
several pathological conditions, such as ischemic stroke, dementia, and vascular cognitive impairment. Although the physiological role of caveolae has been reported in different types of arteries, there have been no studies focusing on the physiological function of caveolae in carotid arteries. Therefore, the aim of this study was to evaluate the effects of caveolar disruption (using MBCD) on the contractility of carotid artery, due to inhibition of NO release and modulation of maxi-K channel activity, to understand the physiological function of the maxi-K channels in the rat carotid artery.

\section{Materials And Methods \\ 2.1. Animals}

Forty adult male Wistar rats (175-200 g) were obtained from King Fahd Medical Research Center, King Abdulaziz University, Saudi Arabia. Rats were kept in a 12-h light/12-h dark cycle. All animals were offered free access to water and laboratory food for a week for adaptation, following which, they were euthanized using high concentrations of $\mathrm{CO}_{2}$.

\subsection{Experimental groups}

Rats were divided into two groups (20 in each group) as follows: treated animals with methyl- $\beta$ cyclodextrin (MBCD) and non-treated animals.

\subsection{Drugs and chemicals}

For depolarization, high potassium physiological saline (KPSS), consisting of a physiological saline solution formed by replacing $\mathrm{NaCl}$ with $80 \mathrm{mM} \mathrm{KCl}$ was used. For inducing contractions of the arteries via activation of L-type $\mathrm{Ca}^{2+}$ channels, BaK, consisting of $200 \mathrm{nM} \pm$ Bay-K8644 $+20 \mathrm{mM} \mathrm{K}^{+}$dissolved in physiological saline solution, was used. For inhibiting nitric oxide synthase, $250 \mu \mathrm{M}$ nitroarginine methyl ester (L-NAME) dissolved in BaK or KPSS, or physiological saline solution was used. Stock solutions of iberiotoxin $(100 \mu \mathrm{M})$ and acetylcholine $10 \mu \mathrm{M}(\mathrm{ACh})$ were prepared in distilled water. MBCD was prepared by dissolving it in a physiological saline solution. Cholesterol-saturated MBCD (Ch-MBCD) (10 mM) was prepared by dissolving it in a physiological saline solution.

\subsection{Histological analysis}

Intact and ED-denuded carotid arteries were used for histological analysis. The ED was removed from the vessel rings by gently rubbing the intimal surface with human hair. Approximately 0.05 -mm-thick sections of carotid arteries were fixed in $10 \%$ formaldehyde fixative. The samples were dehydrated in ethanol for 30 min each. Segments were cleared with xylene and then embedded in paraffin wax. The blocks were cut at a thickness of $12 \mathrm{~mm}$ using a Leica microtome (VT1000 S vibrating blade microtome). The sections were mounted onto slides coated with gelatin. Subsequently, the slides were stained with Ehrlich hematoxylin and eosin (H\&E) (Sina \&Avwioro 2011). For histological examination, the slides were examined using optical microscopy (Leica, DM2500 \& DM2500 LED).

\subsection{Caveolae disassembly in carotid arteries}


For caveolae disassembly from the plasma membrane of carotid arterial tissues, the blood vessels were incubated with MBCD (10 mM) for $1 \mathrm{~h}$ in the treated group with MBCD (Al-Brakati et al. 2015).

\subsection{Transmission electron microscopy}

Small sections of the carotid arteries (0.5-1 mm thick) from each group $(n=10)$ were fixed with $4 \%$ paraformaldehyde and $2.5 \%$ glutaraldehyde in $0.1 \mathrm{M}$ sodium cacodylate $(\mathrm{pH} 7.4)$ for $12 \mathrm{~h}$. Samples were washed in $0.1 \mathrm{M}$ sodium cacodylate, and then post-fixed in $1 \%(\mathrm{w} / \mathrm{v}$ ) osmium tetroxide (OsO4) in sodium cacodylate for $1 \mathrm{~h}$. Segments were incubated with cacodylate for $12 \mathrm{~h}$ and reincubated in $2 \%$ aqueous uranyl acetate for $1 \mathrm{~h}$ before embedding in resin. After this, the segments were dehydrated through a graded series of alcohol (60-100\%), immersed in 100\% acetone, and then embedded in resin. Samples were left in the oven at $60^{\circ} \mathrm{C}$ for $12 \mathrm{~h}$. The block was sectioned $(70-90 \mathrm{~nm})$. The sections were mounted on copper grids, stained with $2 \%$ aqueous uranyl acetate for five min, restained with lead citrate for five min, and left for $12 \mathrm{~h}$ after being washed to dry. A transmission electron microscope (JEOL JEM-1400 series $120 \mathrm{kV}$ ) was used to examine the sections, and the sections were imaged under different magnifications.

\subsection{Myography}

The isometric force of the blood vessels was measured using myography (Myograph System-202CM, Danish, Denmark). In brief, carotid artery segments (about $2 \mathrm{~mm}$ long) were mounted in the myograph, as previously described by Prendergast et al. (2010). Arteries were stimulated to contract by KPSS and/or BaK (Al-Brakati et al. 2015, Thomas et al. 1985). In some carotid arteries, the ED was removed by rubbing the lumen using human hair. Acetylcholine $(10 \mu \mathrm{M})$ was used to confirm the absence of relaxation in the ED-denuded arteries.

\subsection{Western blot analysis}

Western blotting was performed to determine the expression of caveolin-1, caveolin-3, a-actin, and Maxi-K channels in rat carotid artery as described previously (Doronin et al. 2004). In addition, a-actin was used as a specific marker for smooth muscle cells in this experiment. Mouse monoclonal anti-caveolin-1; 1:200, (Catalog No; 610058), and rat polyclonal anti-caveolin-3 1:500 (; Catalog No; 610420) were purchased from BD Biosciences, San Jose, CA, USA. Rabbit polyclonal anti-Maxi-K ${ }^{+}$channel (1:500) (Catalog No; 224033) and mouse monoclonal anti-a-actin (1:300) were purchased from United States Biological, USA. The primary antibodies were diluted with TBST with $5 \%$ milk overnight. Arteries were harvested and lysed with lysis buffer containing $50 \mathrm{mmol} / \mathrm{L}$ Tris- $\mathrm{Cl}$ ( $\mathrm{pH} 7.4), 150 \mathrm{mmol} / \mathrm{L} \mathrm{NaCl}, 1 \% \mathrm{Triton}$ $\mathrm{X}-100,1 \%$ sodium deoxycholate, and a series of protease inhibitors. Samples were separated by SDSPAGE and then transferred to a PVDF membrane. Subsequently, samples were blocked and incubated with primary antibodies at $4^{\circ} \mathrm{C}$ for $12 \mathrm{~h}$. The blots were then incubated with the secondary antibody. The secondary antibody (anti-rabbit lgG) was conjugated to horseradish peroxidase (HRP) and diluted in 5\% milk-TBST (1:5000). Immunolabeling was detected using auto-radiographic hyperfilm (Amersham) placed onto the membrane for $5 \mathrm{~min}$. The images were analyzed using Quantity One software (Bio-Rad, CA, USA). 


\subsection{Statistical analyses}

Data expressed by Myography were transferred to the computer by Axoscope software (Axon Instruments, California, USA). Results were analysed using Axoscope and SigmaPlot 18. Statistical significance was assessed by ANOVA with Duncan's test was used as a post hoc test. The acceptable

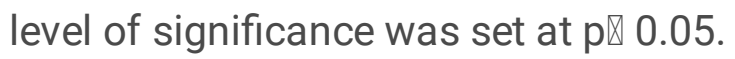

\section{Results}

\subsection{Histological analysis}

Histological examination of the intact carotid arteries revealed normal histological architecture, showing the presence of a single layer of ED in the tunica intima and smooth muscle cells in several layers in the tunica media, as seen in Fig. 1A. In contrast, the histological examination confirmed the absence of ED from tunica media after endothelial removal by human hair (Fig. 1B).

\subsection{Transmission electron microscopy}

\subsubsection{Transmission electron microscopic examination of the intact rat carotid artery}

Transmission electron microscopy of SMCs showed that caveolae were flask-shaped in the cell membrane. It also revealed nanocontacts between caveolae and SR in SMCs, as seen in Fig. 1C. However, caveolae in the endothelial cells of rat carotid arteries were tubule-shaped, as seen in Fig. 1D.

\subsubsection{Transmission electron microscopic examination of the rat carotid artery treated with MBCD}

Transmission electron microscopy showed the abolishment of caveolae in most cell membranes of SMCs and EDs after treatment with MBCD, as seen in Figs. $1 \mathrm{E}$ and $1 \mathrm{~F}$, respectively.

\subsection{Carotid artery contraction analysis}

\subsubsection{Disruption of caveolae by MBCD augmented contraction force of the intact carotid artery}

To evaluate the functional role of caveolae in the rat carotid artery, the contraction force was recorded before and after treatment with MBCD in response to KPSS and BaK. The contraction force analysis showed that the contraction force significantly $(P<0.01)$ augmented $(12.74 \pm 2.15 \mathrm{mN}$ to $19.22 \pm 1.85 \mathrm{mN})$ in response to $\mathrm{BaK}$ after treatment with $\mathrm{MBCD}$. In contrast, no significant change was observed in the contraction force in response to KPSS ( $32.58 \pm 1.43 \mathrm{mN}$ to $33.12 \pm 3.54 \mathrm{mN})$ after treatment with MBCD (Figs. 2A and 2B). This result suggests that disruption of caveolae by MBCD affects the ion channels that regulate contractility. 


\subsubsection{Incubation of the carotid artery with Ch-MBCD reversed the augmented contraction induced by MBCD}

Incubation of the carotid artery with Ch-MBCD $(10 \mathrm{mM})$ reversed the augmented contraction induced by $M B C D$ in response to BaK and significantly altered the contraction force $(19.22 \pm 2.24 \mathrm{mN}$ to $12.55 \pm 2.13$ $\mathrm{mN})$. In addition, no significant effect was observed on the contraction force in response to KPSS $(32.18 \pm 2.52 \mathrm{mN}$ to $32.18 \pm 3.02 \mathrm{mN}$ ) (Figs. $2 \mathrm{~A}$ and $2 \mathrm{~B}$ ). This result suggested that incubation of the carotid artery with Ch-MBCD after disrupting caveolae by MBCD restored the caveolae structure, thereby recovering the ion channels located within caveolae.

\subsubsection{The effect of MBCD on the contraction force is ED- dependent}

The absence of the ED in ED-denuded carotid arteries was confirmed by the loss of a vasodilatory response to acetylcholine. The contraction of ED-denuded carotid arteries showed a nonsignificant augmentation $(12.12 \pm 2.34 \mathrm{mN}$ to $15.22 \pm 3.02 \mathrm{mN})$ in response to BaK after treatment with MBCD. These results suggest that the augmentation of contraction by MBCD is ED-dependent (Figs. 3A and 3B). Moreover, augmented contractions by BaK depend on the vasodilator factors released from the ED.

3.3.4. Incubation of intact carotid arteries with L-NAME augmented the contraction force but had no effect after MBCD treatment

Intact carotid arteries preincubated with $250 \mu \mathrm{M}$ L-NAME showed a significantly augmented contraction in response to $\mathrm{BaK}(\mathrm{P}<0.01)(7.12 \pm 1.50 \mathrm{mN}$ to $16.09 \pm 2.13 \mathrm{mN})$. In contrast, intact carotid arteries preincubated with L-NAME showed no considerable change in the contraction force after MBCD treatment $(16.98 \pm 2.33 \mathrm{mN}$ to $16.09 \pm 2.87 \mathrm{mN})$. These results suggest that caveolar disruption using $M B C D$ leads to reduced release of NO from the ED, subsequently augmenting the contraction force in response to BaK (Figs. 4A and 4B).

3.3.5. Inhibition of the maxi-K channels by iberiotoxin did not increase the contraction force of intact carotid arteries after treatment with MBCD

In this study, iberiotoxin was used as a specific inhibitor of the maxi-K channels (Langton 1993, Langton et al. 1991). Intact carotid arteries preincubated with $100 \mathrm{nM}$ iberiotoxin showed a significant increase $(P<0.05)$ in the contraction force $(6.05 \pm 3.04 \mathrm{mN}$ to $17.80 \pm 2.24 \mathrm{mN})$. This finding suggests that iberiotoxin is a specific inhibitor for the maxi-K channels, consequently contributing to inducing the resting state during contraction with BaK. In addition, arteries incubated with iberiotoxin showed a nonsignificant change in the contraction force $(13.01 \pm 3.01 \mathrm{mN}$ to $16.98 \pm 3.55 \mathrm{mN})$ in response to BaK after treatment with MBCD. This observation suggests that caveolar disruption by MBCD leads to a decreased contribution of iberiotoxin to the physiological function of the maxi-K channels in inducing membrane depolarization in smooth muscle cells (Figs. 5A and 5B). 


\subsubsection{Inhibition of the maxi-K channels by iberiotoxin did not increase the contraction force of ED- removed carotid arteries after treatment with MBCD}

ED-removed carotid arteries incubated with 100 iberiotoxin showed no significant change in the contraction force in response to BaK K before/after incubation with MBCD $(6.75 \pm 1.55 \mathrm{mN}$ to $8.17 \pm 1.19$ $\mathrm{mN})$ and $(7.01 \pm 2.44 \mathrm{mN}$ to $8.30 \pm 2.14 \mathrm{mN})$, respectfully as seen in Figs. $6 \mathrm{~A}$ and $6 \mathrm{~B})$. These results suggested that both caveolar disruption by MBCD and/or ED removal inhibited the release of NO, thereby inhibiting the activation of maxi-K channels, leading to the induction of smooth muscle cell contraction.

\subsubsection{Incubation of intact carotid arteries with iberiotoxin inhibited the release of basal NO from the ED}

In this study, further experiments were designed to examine the physiological role of the maxi-K channels in the release of NO from the ED. The result of the experiment showed that adding iberiotoxin at the peak contraction induced by BaK caused a significant change $(P<0.01)$ in the contraction force from 5.75 $\pm 1.22 \mathrm{mN}$ to $13.45 \pm 1.12 \mathrm{mN}$ in the absence of L-NAME. However, adding iberiotoxin at the peak contraction to the vessels incubated with L-NAME caused a nonsignificant change in contraction force in response to $B a K(14.14 \pm 1.05 \mathrm{mN}$ to $16.88 \pm 1.33 \mathrm{mN})$. These findings suggest that the augmented contraction caused by iberiotoxin was markedly inhibited by L-NAME (Figs. 7A and 7B). This reflects the contribution of the max-K channel in releasing NO from the ED, which leads to activation of the maxi-K channels in vascular smooth muscle cells.

\subsection{Western blot analysis}

In this study, western blotting was performed to examine the expression of caveolin-1, caveolin-3, maxi-K channels, and a-actin in protein lysates of rat carotid arteries. Western blotting revealed caveolin-1 expression at $24-\mathrm{kDa}$, caveolin-3 at $18-\mathrm{kDa}$, and maxi-K channels at $96-\mathrm{kDa}$. These findings prove that the caveolae proteins (caveolins) and the Maxi-K channels were expressed in rat carotid artery tissues. In addition, the expression of a-actin was observed at $42-\mathrm{kDa}$, which was considered a specific marker for smooth muscle cells in this experiment, as shown in Fig. 8.

\section{Discussion}

The results of this study showed that caveolae disassembly using MBCD augmented the contraction in response to BaK but not to KPSS. In this study, the experiment was designed to augment the contraction by high- $\mathrm{K}(80 \mathrm{Mm} \mathrm{KCl})$, which induces the equilibrium potential for $\mathrm{K}$ ions throughout the cell membrane of the smooth muscle cells. Therefore, the high- $\mathrm{K}^{+}$-induced contraction is not affected by calciummediated contractions via voltage-dependent calcium channels (Meisheri et al. 1990). In addition, Bay K8644 was primarily used in this study as a specific calcium channel agonist (Thomas et al. 1985). These results agree with the findings of (Al-Brakati et al. 2015), who demonstrated that the augmented contraction in different arteries is due to disruption of caveolae by MBCD(Gimpl et al. 1997, Rothberg et al. 1990). Several studies have reported that caveolae play an important role in the regulation of arterial tone. In other studies, it has been reported that disruption of caveolae impairs vasorelaxation and causes 
several vascular diseases, including atherosclerosis (Darblade et al. 2001, Radenković et al. 2012, Xu et al. 2008). However, the augmented contraction by MBCD in response to BaK was reversed after incubation of the carotid segment with Ch-MBCD. The results of this study indicate that the increase in the contraction force was regulated by cholesterol depletion. These results suggest that caveolar disruption using MBCD leads to reduced release of NO from the ED. However, in this regard, it has been reported that cholesterol has inhibitory effects on the ion channels of the blood vessels (Levitan et al. 2014). A similar result was reported by (Al-Brakati et al. 2015), that the augmented contraction by MBCD in response to BaK was reversed after incubation of the femoral segment with Ch-MBCD.

The physiological role of $\mathrm{NO}$ in vasorelaxation has been shown in several studies (Ahmad et al. 2018, Herrera \&Garvin 2007, Lumley et al. 2016). It has been reported that adding acetylcholine as an EDdependent vasodilator has no effect on arterial relaxation (Drab et al. 2001, Razani \&Lisanti 2001). However, the association between caveolin-1 and eNOS, which causes tonic inhibition of enzyme activity, has been shown in different kinds of blood vessels (Michel et al. 1997).

Many factors are involved in the basal release of NO, including ED-dependent vasodilators such as acetylcholine (Michel \&Vanhoutte 2010). In this study, another experiment was performed to evaluate the role of NO in vasorelaxation in rat carotid arteries. The results of this study showed that incubation of EDintact carotid arteries with L-NAME abolished the vasodilator response to Ach and augmented the contraction response to BaK. In addition, we found that L-NAME did not augment the contractile force after MBCD treatment in response to BaK. These results suggested that vasorelaxation of rat carotid artery was dependent on NO release from the ED cells, and caveolar disruption using MBCD impaired EDdependent relaxation.

In a step to confirm the contributing role of basal NO released from the ED to increase contraction, the EDdenuded carotid arteries were incubated with L-NAME. A slight augmentation in contraction in response to BaK was observed. These findings suggest that $\mathrm{NO}$ is the key mediator of vasorelaxation in rat carotid arteries. These results agree with the findings of Darblade et al. (2001), who reported that caveolae disruption mimics endothelial dysfunction in rabbit aorta.

To study the effects of maxi-K channel inhibitors on smooth muscle cell contraction, blocking the maxi-K channels by iberiotoxin showed a marked increase in contraction force in response to BaK, and about $25 \%$ in ED-denuded arteries. However, the larger contraction was showed in intact ED, might be indicated to the maiger role of $\mathrm{NO}$ inactivate the maxi-K channel in rat carotid arteries. In contrast, the low $\mathrm{Ca}^{2+}$ sensitivity of the channel may explain the comparatively small contribution to membrane potential, and thus, increase contraction. These results evidently indicate the participation of the maxi-K channels to induce membrane potential, thus increasing the contraction. However, Maxi-K channels have been previously implicated in NO-induced vasorelaxation in blood vessels (Hu \&Zhang 2012, Khan et al. 1998).

To study the effects of caveolar disruption on smooth muscle cell contraction, the ED-denuded carotid arteries were incubated with iberiotoxin. No significant augmentation of the contraction force in response 
to BaK before and/or after treatment with MBCD was observed. The first explanation for these findings is that NO released from the endothelial cells induces vasorelaxation through maxi-K channel activation in smooth muscle cells. It is well known that nitrovasodilators act to initiate vasorelaxation via potassium channel opening. The mechanism of regulation of maxi-K channels by NO includes activation of guanylate cyclase. Subsequently, the generation of cGMP, activation of cGMP-dependent PKC, and thus, the activation of smooth muscle cell maxi-K channels occurs (Robertson et al. 1993). The second explanation is that the inhibition of eNOS-activity through caveolin- 1 occurs in the absence of $\mathrm{Ca}^{2+}-\mathrm{CaM}$ (Sandow et al. 2002). This might decrease $\mathrm{Ca}^{2+}$-dependent activation of eNOS, reduce NO release, and subsequently augment the contraction of the carotid artery. However, several studies have demonstrated the presence of maxi-K channels in endothelial cells (Sandow \&Grayson 2009).

Furthermore, caveolar disruption in smooth muscle cells has been shown to change the response to some ion channels and receptors located within caveolae in the vascular tissue (Dreja et al. 2002, Parton et al. 1997, Prendergast et al. 2010). The disturbance in the cholesterol amount in the plasma membrane has been associated with increased contraction in some arteries due to inhibition of potassium channels, which leads to inhibition of calcium channels (Catterall 2011). In general, these results explain the importance of the receptors and ion channels located within caveolae, which contribute to the contractile response.

In this study, transmission electron microscopy was used to observe the presence of caveolae in the plasma membrane in both SMCs and ECs. It was also used to confirm the absence of caveolae from the plasma membrane of the SMCs and EDs after treatment with MBCD. Transmission electron microscopy revealed the presence of caveolae throughout the plasma membrane in the ED and smooth muscle cells in the intact rat carotid artery. In contrast, after pretreatment of the rat carotid artery with MBCD, the transmission electron microscope revealed abolished caveolae from most of the plasma membrane of the ED and smooth muscle cells in the rat carotid artery. These results agree with several studies reported by (Al-Brakati et al. 2015, Cohen et al. 2004, Dreja et al. 2002, Khan et al. 1998, Xu et al. 2008), who demonstrated caveolae in the ED and smooth muscle cells in different arteries. In addition, they reported the abolishment of caveolae from the cell membrane of the ED and SMCs after the treatment of the arteries with MBCD.

\section{Conclusion}

This study concluded that caveolar disruption using MBCD impaired the ED-dependent relaxation, inhibiting the release of NO from the ED, and altered the contractility of smooth muscle cells (SMCs) independently of the ED due to reduced contribution of maxi-K channels to the SMC membrane potential, causing depolarization and increased carotid artery contraction (Fig. 9). Therefore, these findings might help to understand the physiological role of the Maxi-K channels in rat carotid arteries.

\section{Declarations}


Author's contribution: The author has performed all the research items.

Funding: Self-funding

Data availability: Available upon request.

Conflict of interest: The author declares that there is no conflict of interest.

Ethical approval: All the steps and procedures of this experiment were approved by the Committee of Research Ethics for Laboratory Animal Care, Taif University, Saudi Arabia. (approval no. TU000678).

Consent to Participate: Not applicable.

Consent to Publish: Consented.

\section{References}

1. Ahmad A, Dempsey SK, Daneva Z, Azam M, Li N, Li P-L, Ritter JK (2018) Role of Nitric Oxide in the Cardiovascular and Renal Systems. Int J Mol Sci 19:2605

2. Al-Brakati A, Kamishima T, Dart C, Quayle J (2015) : Caveolar disruption causes contraction of rat femoral arteries via reduced basal NO release and subsequent closure of BKCa channels.PeerJ3, e966

3. Andjelkovic AV, Stamatovic SM, Phillips CM, Martinez-Revollar G, Keep RF (2020) Modeling bloodbrain barrier pathology in cerebrovascular disease in vitro: current and future paradigms. Fluids and Barriers of the CNS 17:1-21

4. Bender F, Montoya M, Monardes V, Leyton L, Quest AF (2002) Caveolae and caveolae-like membrane domains in cellular signaling and disease: identification of downstream targets for the tumor suppressor protein caveolin-1. Biol Res 35:151-167

5. Berg J, Tymoczko J, Stryer L (2002) : Section 30.2, each organ has a unique metabolic profile. Biochemistry

6. Bosmia AN, Hogan E, Loukas M, Tubbs RS, Cohen-Gadol AA (2015) Blood supply to the human spinal cord: part I. Anatomy and hemodynamics. Clin Anat 28:52-64

7. Catterall WA (2011) Voltage-gated calcium channels. Cold Spring Harb Perspect Biol 3:a003947

8. Chen Z, Oliveira DS, Zimnicka S, Jiang AM, Sharma Y, Chen T, Lazarov S, Bonini O, Haus MG, Minshall JM RD (2018) Reciprocal regulation of eNOS and caveolin-1 functions in endothelial cells. Mol Biol Cell 29:1190-1202

9. Cohen AW, Hnasko R, Schubert W, Lisanti MP (2004) Role of caveolae and caveolins in health and disease. Physiol Rev 84:1341-1379

10. Darblade B, Caillaud D, Poirot M, Fouque M-J, Thiers J-C, Rami J, Bayard F, Arnal J-F (2001) Alteration of plasmalemmal caveolae mimics endothelial dysfunction observed in atheromatous rabbit aorta. Cardiovascular Res 50:566-576 
11. Doronin SV, Potapova IA, Lu Z, Cohen IS (2004) Angiotensin receptor type 1 forms a complex with the transient outward potassium channel Kv4. 3 and regulates its gating properties and intracellular localization. J Biol Chem 279:48231-48237

12. Drab M, Verkade P, Elger M, Kasper M, Lohn M, Lauterbach B, Menne J, Lindschau C, Mende F, Luft FC (2001) : Loss of caveolae, vascular dysfunction, and pulmonary defects in caveolin-1 genedisrupted mice. science 293, 2449-2452

13. Dreja K, Voldstedlund M, Vinten J, Tranum-Jensen J, Hellstrand P, Swärd K (2002) : Cholesterol depletion disrupts caveolae and differentially impairs agonist-induced arterial contraction. Arteriosclerosis, thrombosis, and vascular biology 22, 1267-1272

14. Fridolfsson HN, Roth DM, Insel PA, Patel HH (2014) Regulation of intracellular signaling and function by caveolin. FASEB J 28:3823-3831

15. Ghosh P, Mora Solis FR, Dominguez JM 2, Spier SA, Donato AJ, Delp MD, Muller-Delp JM (2015) : Exercise training reverses aging-induced impairment of myogenic constriction in skeletal muscle arterioles. J Appl Physiol (1985) 118, 904-911

16. Gimpl G, Burger K, Fahrenholz F (1997) Cholesterol as modulator of receptor function. Biochemistry 36:10959-10974

17. Gu X, Reagan AM, McClellan ME, Elliott MH (2017) Caveolins and caveolae in ocular physiology and pathophysiology. Prog Retin Eye Res 56:84-106

18. Herrera M, Garvin JL (2007) Novel role of AQP-1 in NO-dependent vasorelaxation. American Journal of Physiology-Renal Physiology 292:F1443-F1451

19. Hu X-Q, Zhang L (2012) Function and regulation of large conductance $\mathrm{Ca}(2+)$-activated $\mathrm{K}+$ channel in vascular smooth muscle cells. Drug Discov Today 17:974-987

20. Khan SA, Higdon NR, Meisheri KD (1998) Coronary vasorelaxation by nitroglycerin: involvement of plasmalemmal calcium-activated $\mathrm{K}+$ channels and intracellular Ca++ stores. J Pharmacol Exp Ther 284:838-846

21. Langton $P$, Nelson $M$, Huang $Y$, Standen N (1991) Block of calcium-activated potassium channels in mammalian arterial myocytes by tetraethylammonium ions. Am J Physiol Heart Circ Physiol 260:H927-H934

22. Langton $P$ (1993) Calcium channel currents recorded from isolated myocytes of rat basilar artery are stretch sensitive. J Physiol 471:1-11

23. Levitan I, Singh DK, Rosenhouse-Dantsker A (2014) Cholesterol binding to ion channels. Front Physiol 5:65

24. Lian X, Matthaeus C, Kaßmann M, Daumke O, Gollasch M (2019a) Pathophysiological Role of Caveolae in Hypertension. Front Med (Lausanne) 6:153-153

25. Lian X, Matthaeus C, Kaßmann M, Daumke O, Gollasch M (2019b) : Pathophysiological Role of Caveolae in Hypertension.Front Med (Lausanne)6 
26. Lumley M, Williams R, Asrress KN, Arri S, Briceno N, Ellis H, Rajani R, Siebes M, Piek JJ, Clapp B (2016) Coronary physiology during exercise and vasodilation in the healthy heart and in severe aortic stenosis. J Am Coll Cardiol 68:688-697

27. Meisheri KD, Dubray LAC, Oleynek JJ (1990) A sensitive in vitro functional assay to detect K+channel-dependent vasodilators. Journal of pharmacological methods 24:251-261

28. Michel JB, Feron O, Sacks D, Michel T (1997) Reciprocal regulation of endothelial nitric-oxide synthase by Ca2+-calmodulin and caveolin. J Biol Chem 272:15583-15586

29. Michel T, Vanhoutte PM (2010) Cellular signaling and NO production. Pflügers Archiv-European Journal of Physiology 459:807-816

30. Miyagi Y, Kobayashi S, Nishimura J, Fukui M, Kanaide H (1996) Dual regulation of cerebrovascular tone by UTP: P2U receptor-mediated contraction and endothelium-dependent relaxation. $\mathrm{Br} \mathrm{J}$ Pharmacol 118:847-856

31. Nakada T, Kwee IL (2019) Fluid Dynamics Inside the Brain Barrier: Current Concept of Interstitial Flow, Glymphatic Flow, and Cerebrospinal Fluid Circulation in the Brain. Neuroscientist 25:155-166

32. Parton RG, Way M, Zorzi N, Stang E (1997) Caveolin-3 associates with developing T-tubules during muscle differentiation. J Cell Biol 136:137-154

33. Prendergast C, Quayle J, Burdyga T, Wray S (2010) Cholesterol depletion alters coronary artery myocyte Ca2+ signalling in a stimulus-specific manner. Cell Calcium 47:84-91

34. Radenković M, Stojanović M, Janković R, Topalović M, Stojiljković M (2012) : Combined contribution of endothelial relaxing autacoides in the rat femoral artery response to CPCA: an adenosine A2 receptor agonist. The Scientific World Journal 2012

35. Razani B, Lisanti MP (2001) Caveolin-deficient mice: insights into caveolar function human disease. J Clin Investig 108:1553-1561

36. Robertson BE, Schubert R, Hescheler J, Nelson MT (1993) cGMP-dependent protein kinase activates Ca-activated K channels in cerebral artery smooth muscle cells. American Journal of Physiology-Cell Physiology 265:C299-C303

37. Rothberg KG, Ying Y-S, Kamen BA, Anderson R (1990) Cholesterol controls the clustering of the glycophospholipid-anchored membrane receptor for 5-methyltetrahydrofolate. J Cell Biol 111:29312938

38. Rothberg KG, Heuser JE, Donzell WC, Ying Y-S, Glenney JR, Anderson RG (1992) Caveolin, a protein component of caveolae membrane coats. Cell 68:673-682

39. Sandow SL, Tare M, Coleman HA, Hill CE, Parkington HC (2002) Involvement of myoendothelial gap junctions in the actions of endothelium-derived hyperpolarizing factor. Circul Res 90:1108-1113

40. Sandow SL, Grayson TH (2009) Limits of isolation and culture: intact vascular endothelium and BKCa. Am J Physiol Heart Circ Physiol 297:H1-H7

41. Sato K, Sadamoto T, Hirasawa A, Oue A, Subudhi AW, Miyazawa T, Ogoh S (2012) Differential blood flow responses to COâ,, in human internal and external carotid and vertebral arteries. J Physiol 
590:3277-3290

42. Shekhar S, Liu R, Travis OK, Roman RJ, Fan F (2017) : Cerebral autoregulation in hypertension and ischemic stroke: a mini review. Journal of pharmaceutical sciences and experimental pharmacology 2017, 21

43. Sina I, Avwioro G (2011) : A NEW HAEMATOXYLIN STAIN FOR THE DEMONSTRATION OF NUCLEAR AND EXTRA NUCLEAR SUBSTANCES. 1

44. Sowa G, Pypaert M, Sessa WC (2001) : Distinction between signaling mechanisms in lipid rafts vs. caveolae. Proceedings of the National Academy of Sciences 98, 14072-14077

45. Thomas G, Chung M, Cohen CJ (1985) A dihydropyridine (Bay k 8644) that enhances calcium currents in guinea pig and calf myocardial cells. A new type of positive inotropic agent. Circ Res 56:87-96

46. Toselli M, Biella G, Taglietti V, Cazzaniga E, Parenti M (2005) Caveolin-1 Expression and Membrane Cholesterol Content Modulate N-Type Calcium Channel Activity in NG108-15 Cells. Biophys J 89:2443-2457

47. Touyz RM, Alves-Lopes R, Rios FJ, Camargo LL, Anagnostopoulou A, Arner A, Montezano AC (2018) Vascular smooth muscle contraction in hypertension. Cardiovascular Res 114:529-539

48. Wong A, Ye M, Levy A, Rothstein J, Bergles D, Searson PC (2013) The blood-brain barrier: an engineering perspective. Frontiers in neuroengineering 6:7

49. Xu Y, Buikema H, van Gilst WH, Henning RH (2008) Caveolae and endothelial dysfunction: filling the caves in cardiovascular disease. Eur J Pharmacol 585:256-260

50. Zundel W, Swiersz LM, Giaccia A (2000) Caveolin 1-mediated regulation of receptor tyrosine kinaseassociated phosphatidylinositol 3-kinase activity by ceramide. Mol Cell Biol 20:1507-1514

\section{Figures}



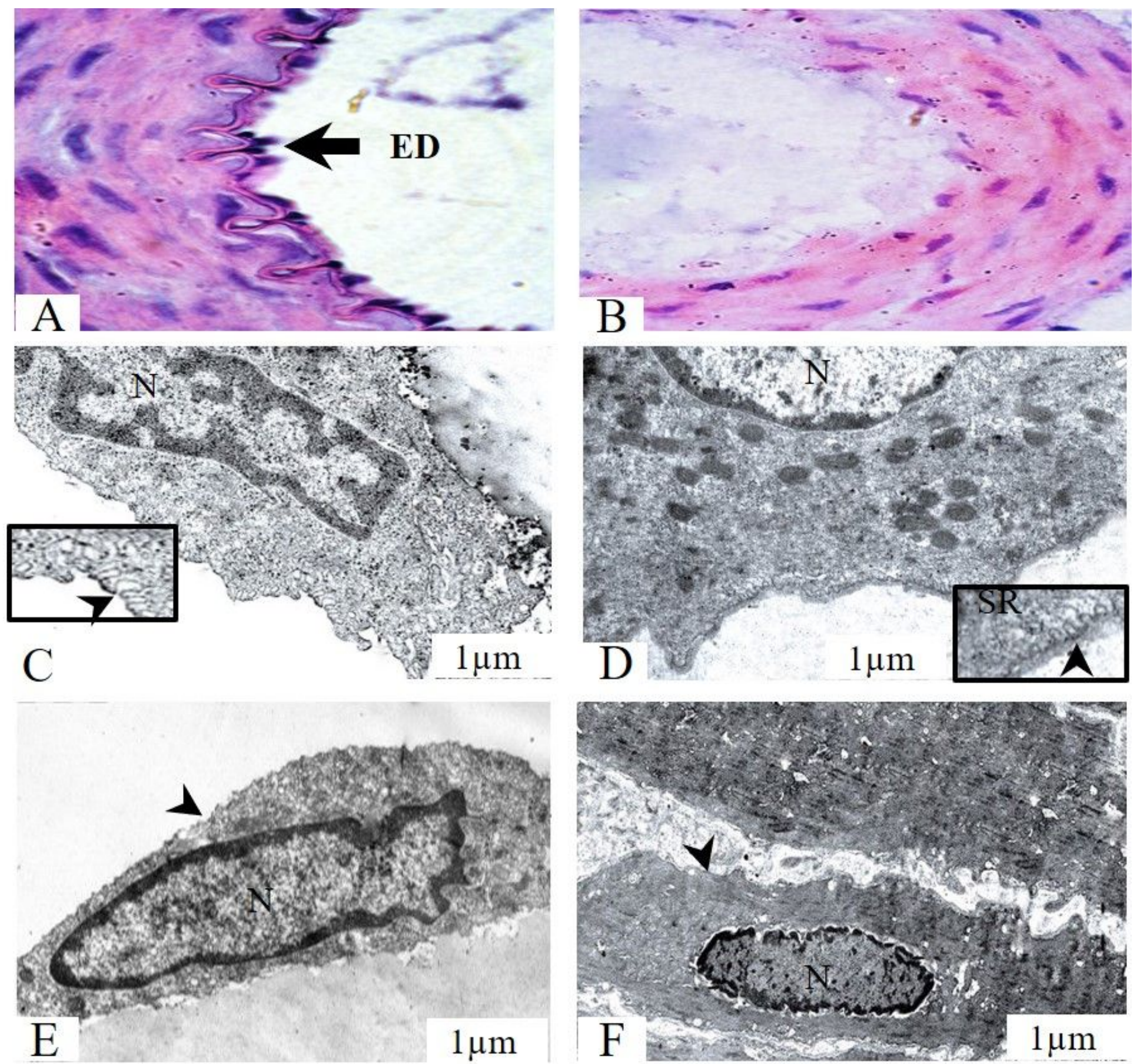

\section{Figure 1}

A. Light photomicrograph showing the normal histologic architecture of the intact rat carotid artery. B. Light photomicrograph showing the absence of the ED layer from tunica media after endothelial removal by human hair. C. Transmission electron micrograph of rat carotid artery shown the caveolae (Cav) covering most of the SMCs membrane (X40000). D. Transmission electron micrograph of rat carotid artery shown the caveolae (Cav) covering most of the ED membrane (X20000). E. Transmission electron micrograph of rat carotid artery shown the cell membranes of SMC free of caveolae after treatment with $M-\beta-C D(X 40000)$. F. Transmission electron micrograph of rat carotid artery shown the cell membranes of ED free of caveolae after treatment with M- $\beta-C D(X 20000)$. 


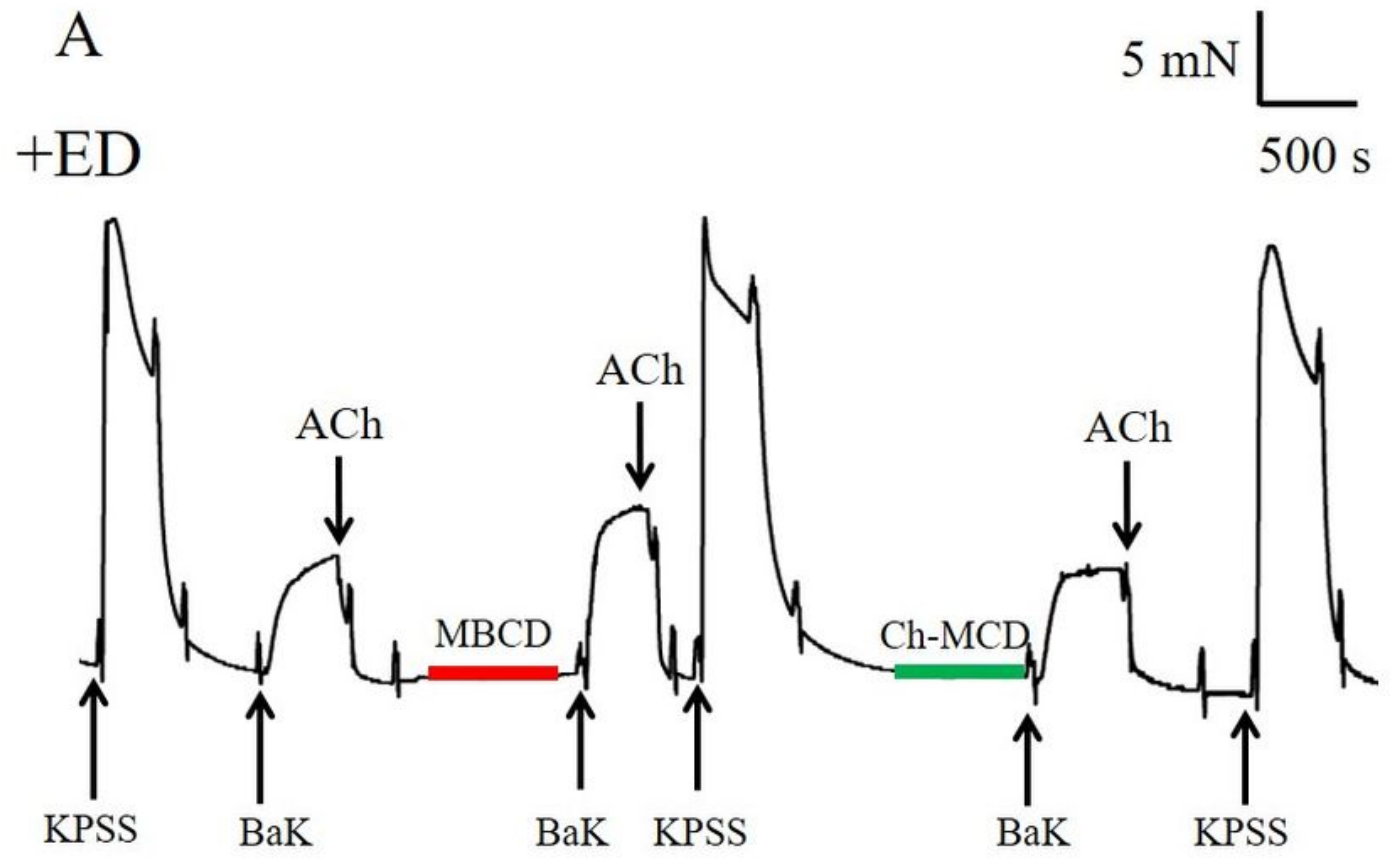

B

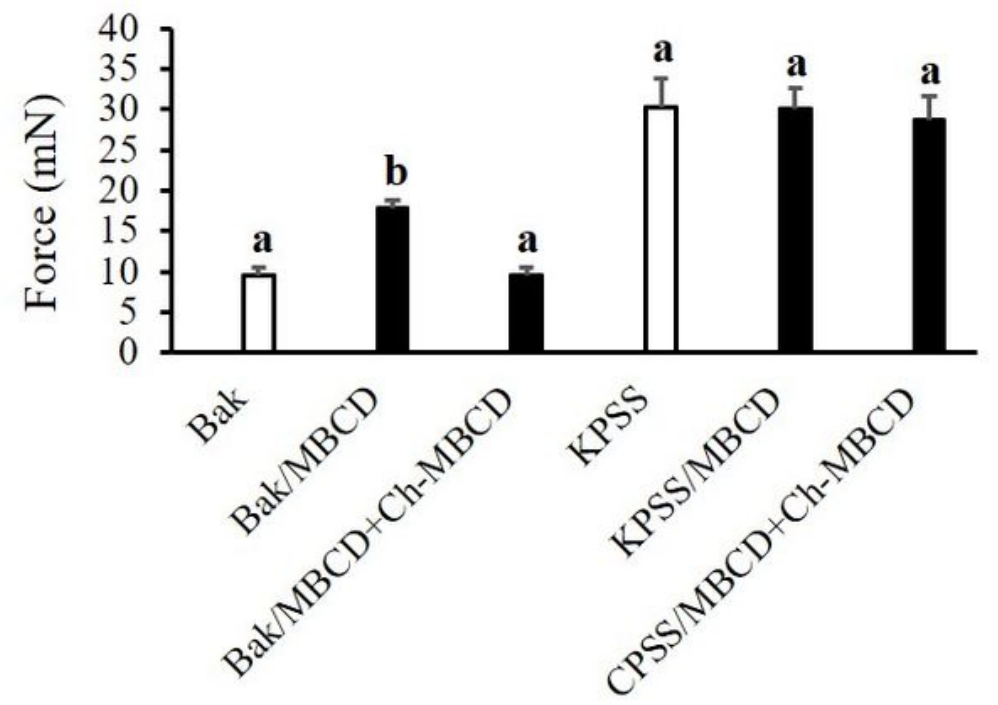

Figure 2

A. Representative force myograph traces showing the effect of Ch-MBCD on contraction force following $M B C D$ treatment in the intact carotid artery. B. Mean data showing the effect of MBCD and Ch-MBCD on 
contractions BaK and KPSS. Data are expressed as means \pm SD $(n=10)$. P-value $<0.05$ was considered statistically significant.
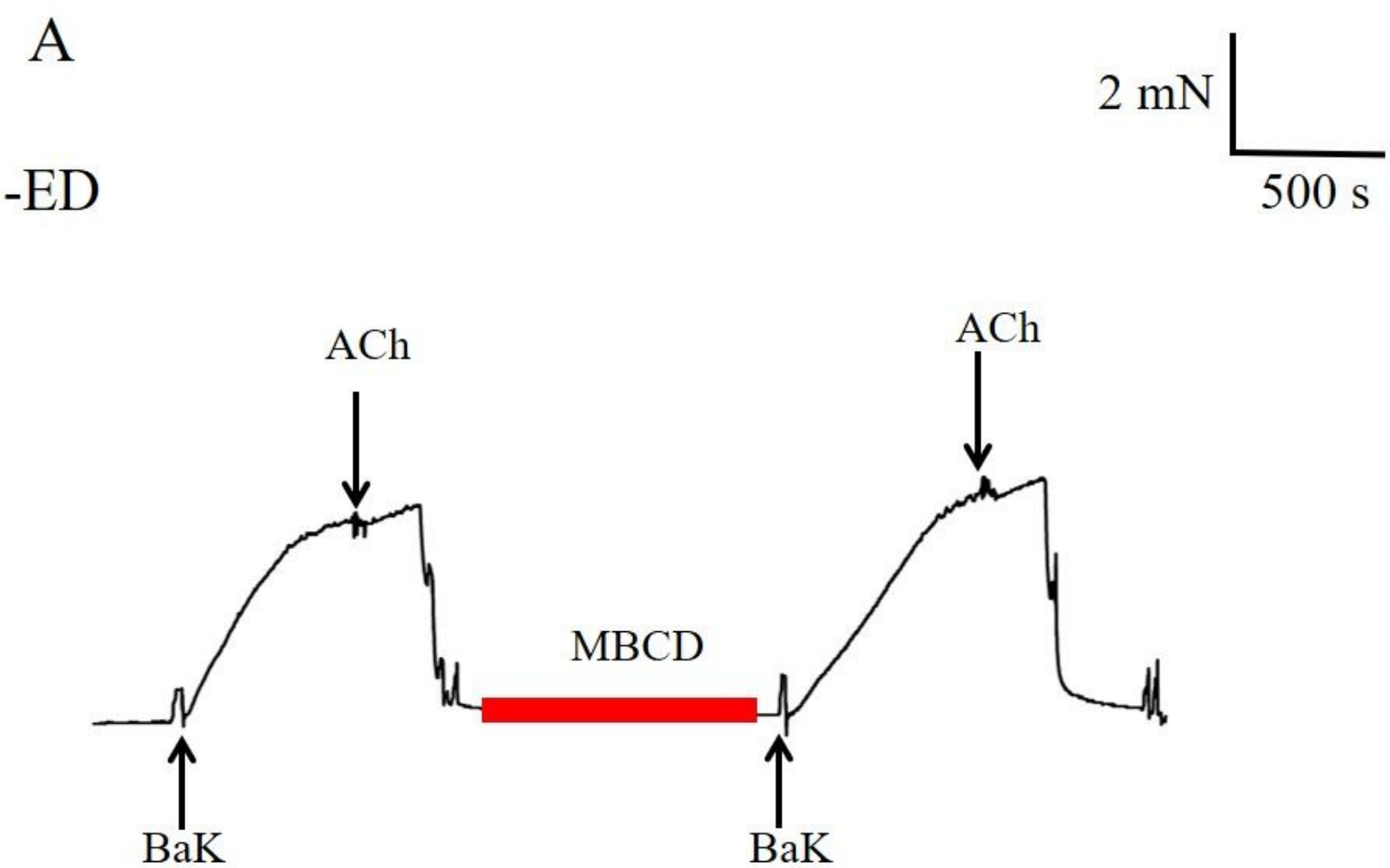

B

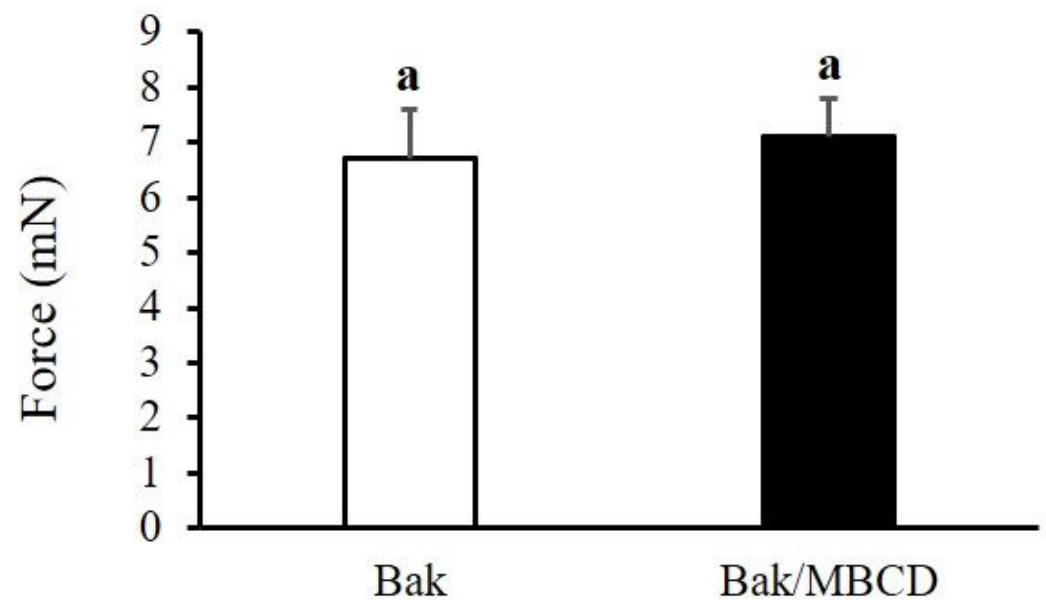

Figure 3

A. Representative force myograph traces showing the effect of MBCD on contraction force in the EDdenuded carotid artery. B. Mean data showing the effect of ED-removal on the contraction force 
stimulated with BaK following MBCD treatment. Data are expressed as means \pm SD $(n=10)$. P-value $<0.05$ was considered statistically significant.

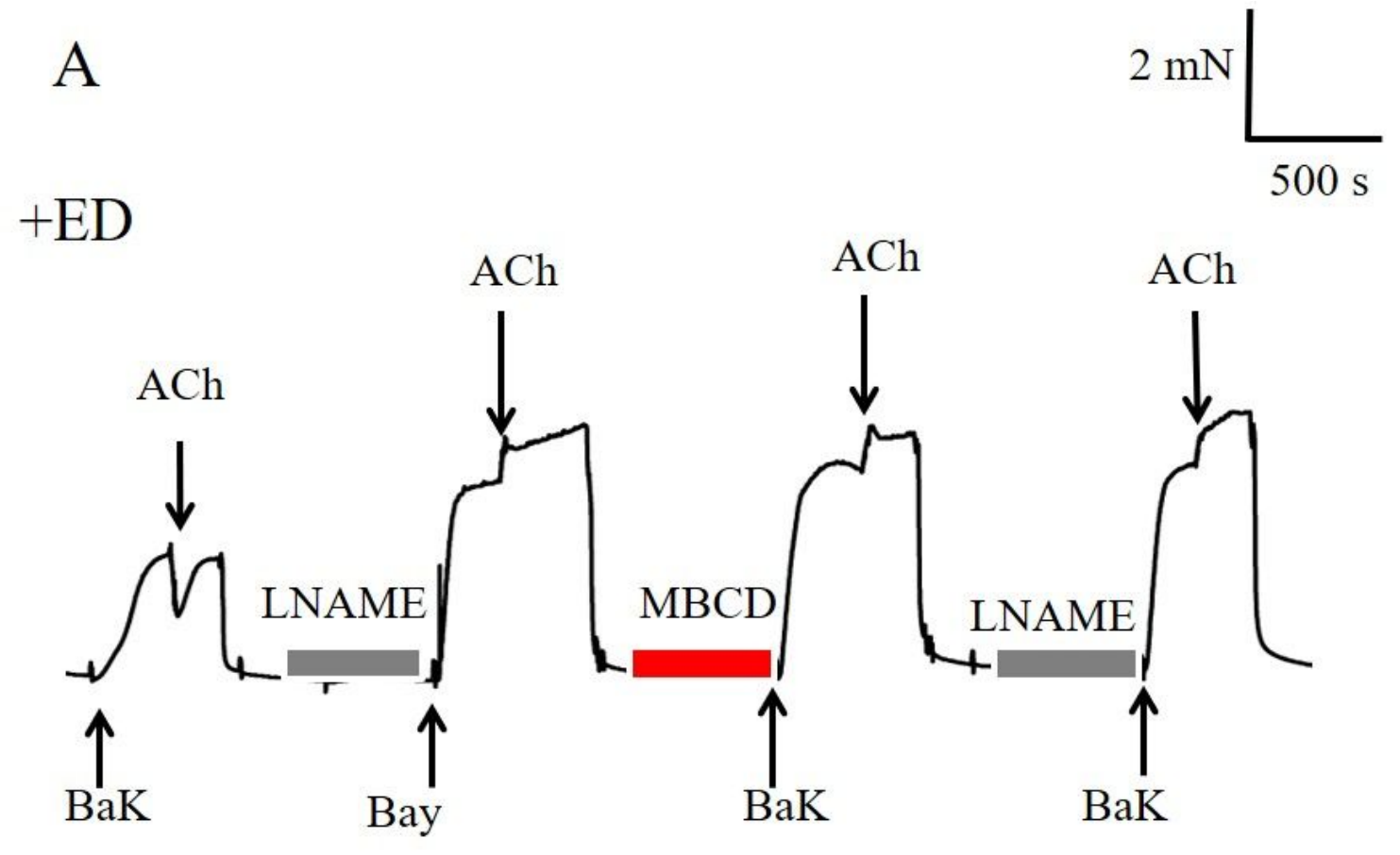

$\mathrm{B}$

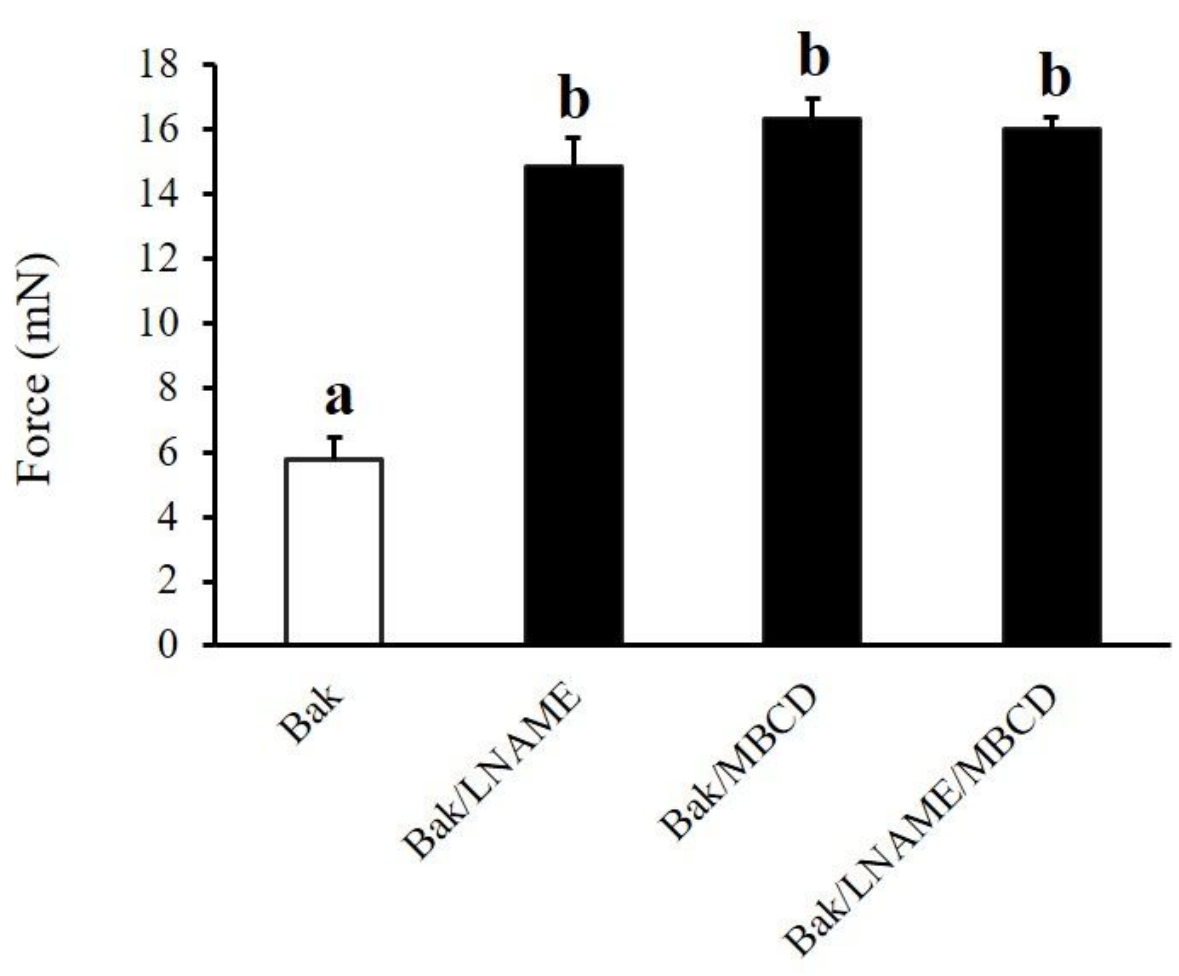

Figure 4 
A. Representative force myograph traces showing the effect of inhibition of NO synthase by L-NAME on intact carotid artery contractions. B. Mean data showing the effect of L-NAME on the contraction response to BaK. Data are expressed as means \pm SD $(n=10)$. P-value $<0.05$ was considered statistically significant.

A

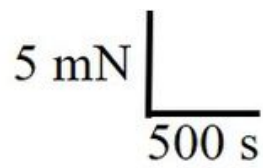

$+\mathrm{ED}$

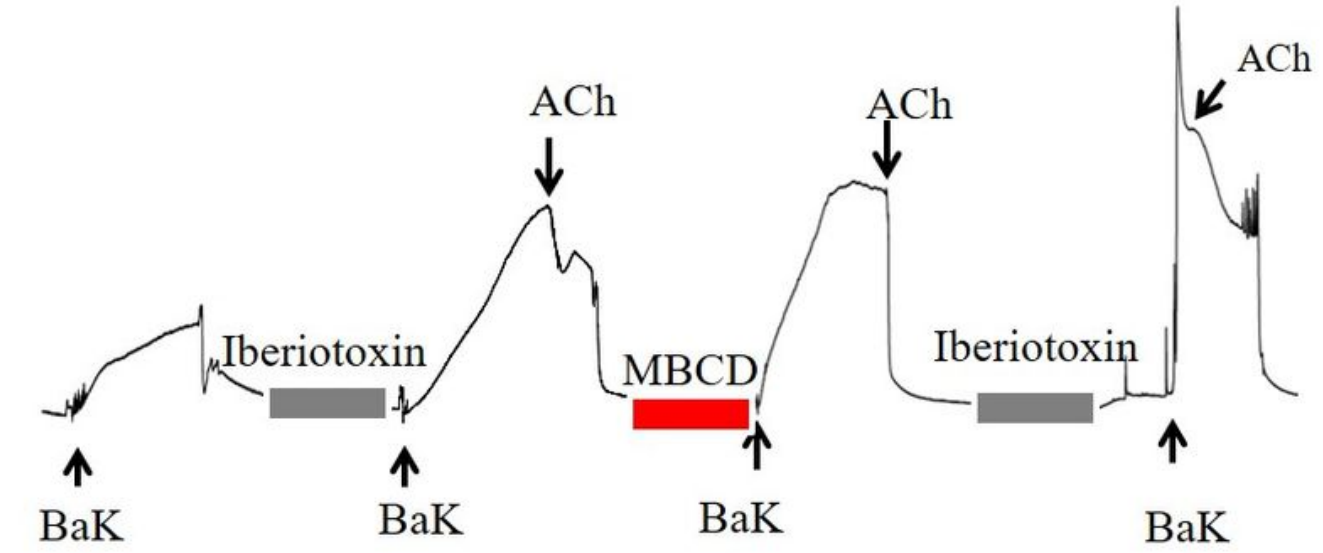

B

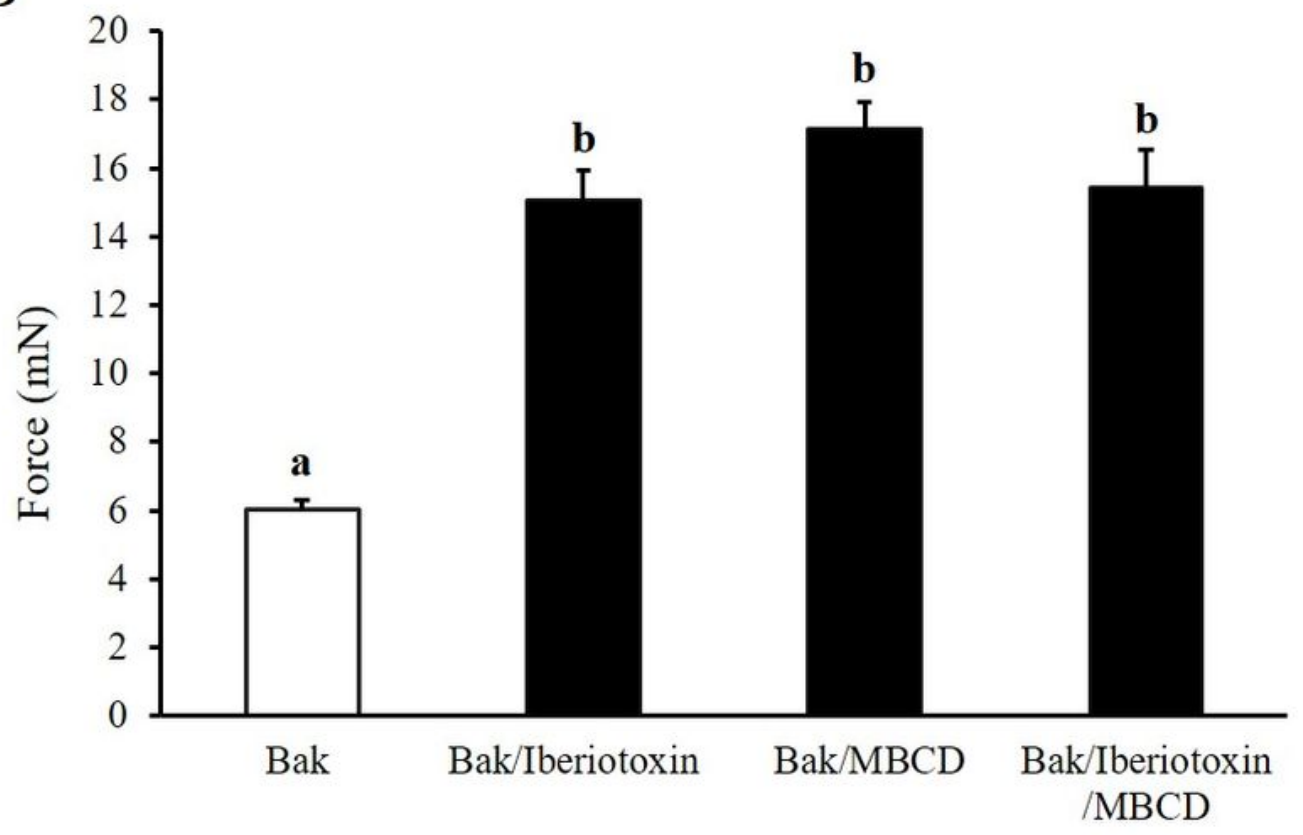




\section{Figure 5}

A. Representative force myograph traces showing the effect of iberiotoxin on contractions with BaK in an intact carotid artery. B. Mean data showing the effect of iberiotoxin on the contraction response to BaK, before/after incubation with MBCD. Data are expressed as means \pm SD $(n=10)$. P-value $<0.05$ was considered statistically significant. 
-ED

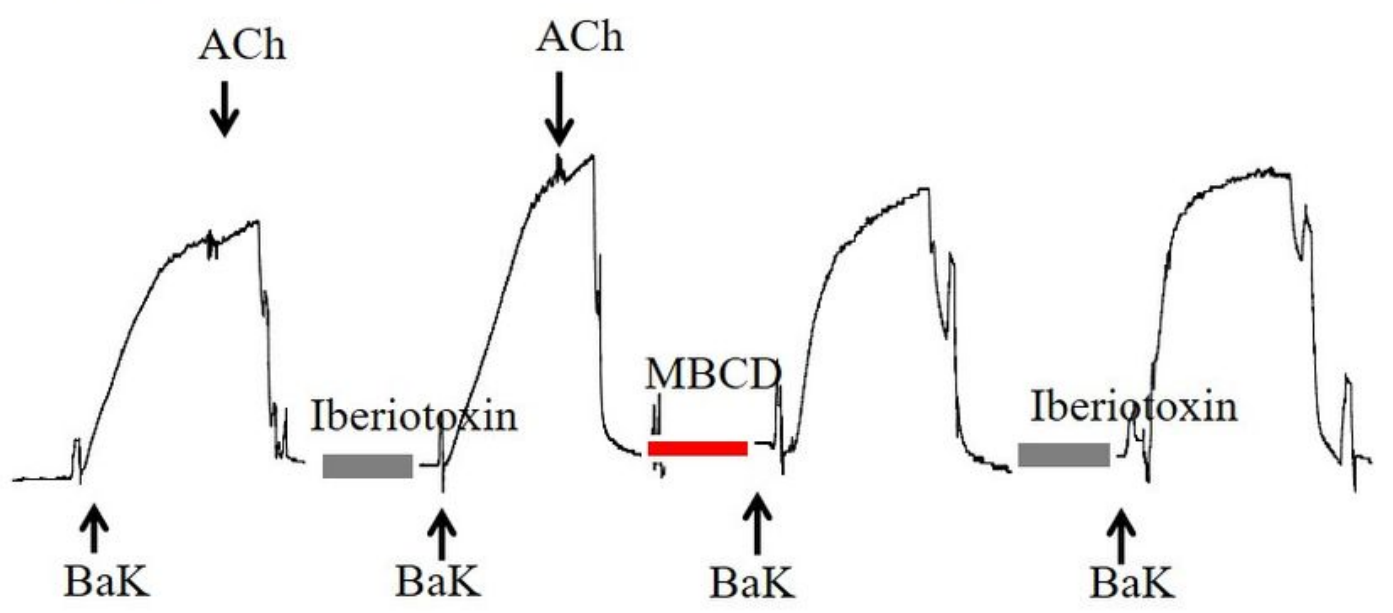

$\mathrm{B}$

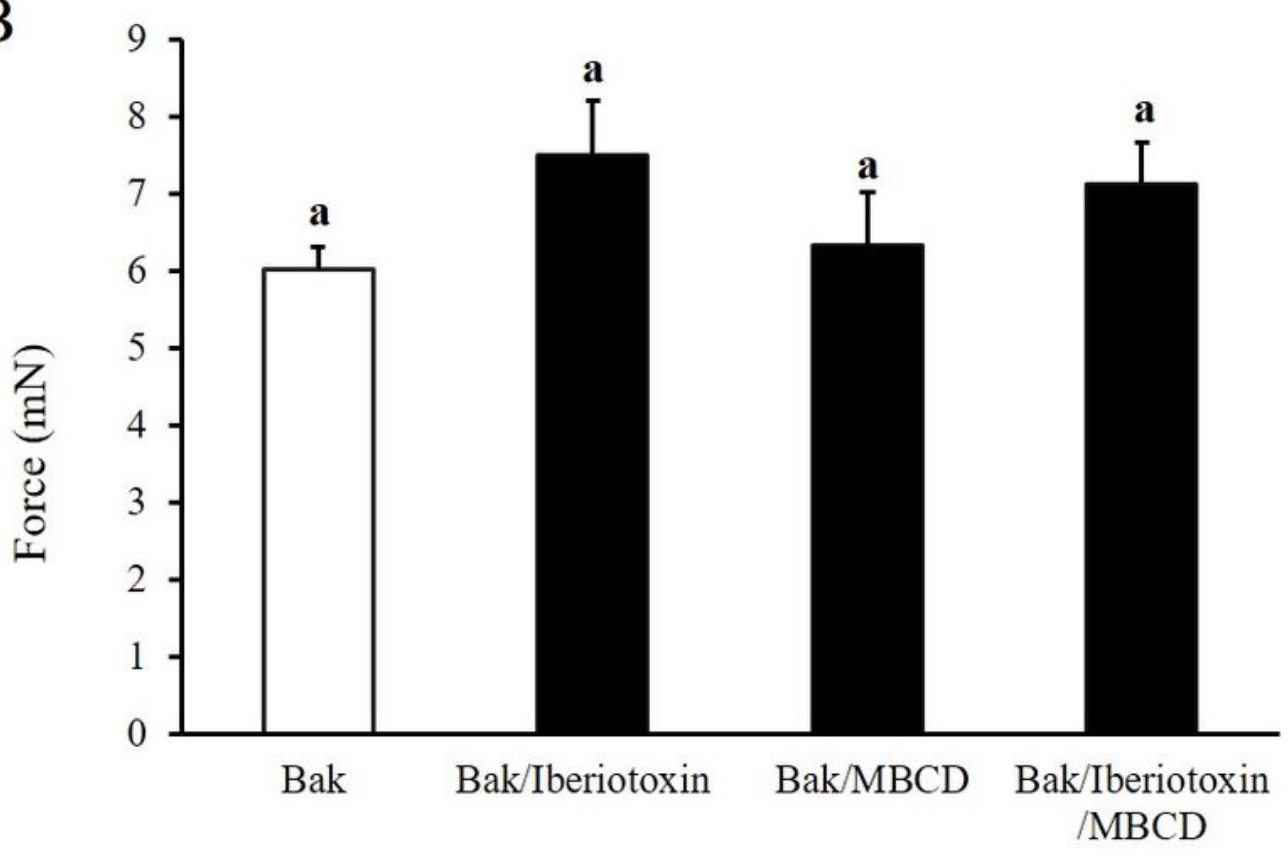

Figure 6

A. Representative force myograph traces showing the effect of iberiotoxin on contraction force in the EDremoved carotid artery in response to BaK. B. Mean data showing the effect of iberiotoxin on the contraction response to BaK after/before incubation with the ED removed. Data are expressed as means \pm SD $(n=10)$. P-value $<0.05$ was considered statistically significant. 


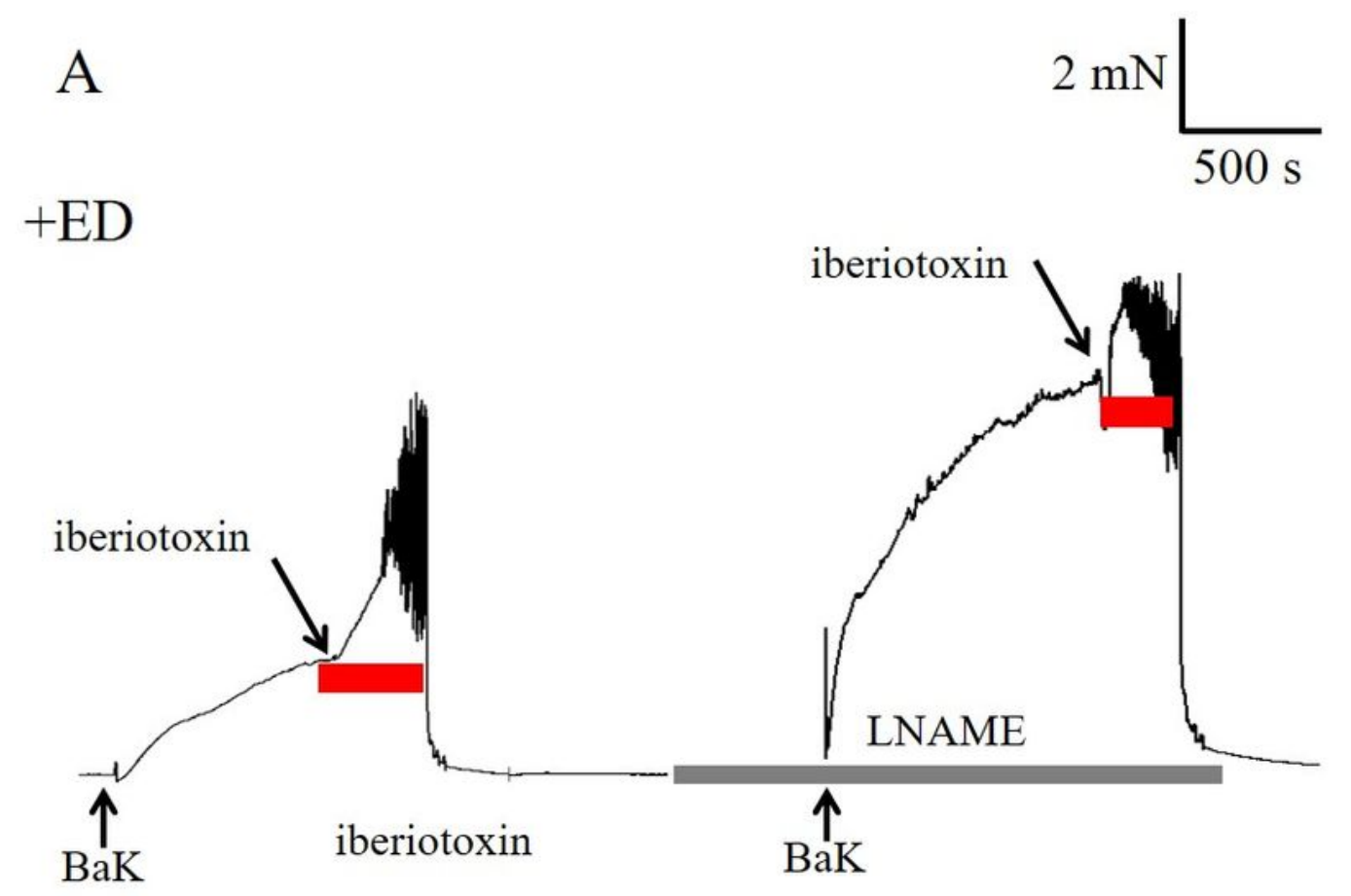

B

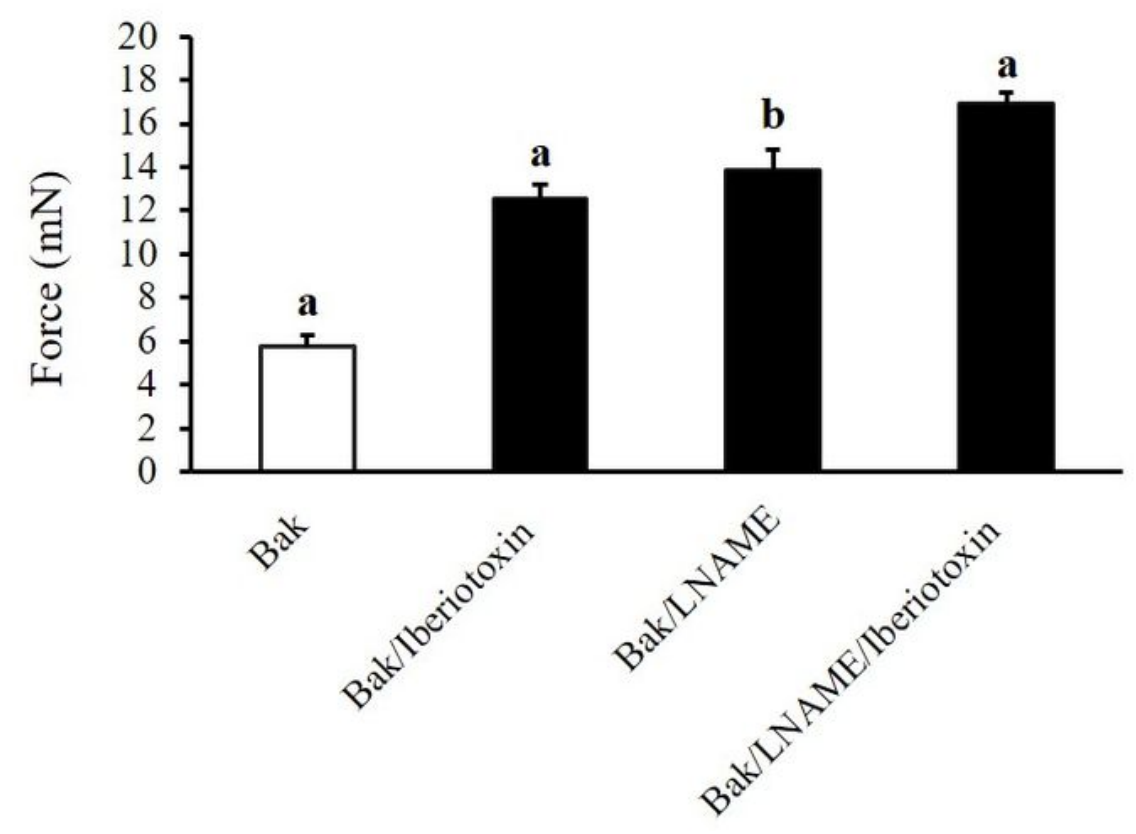

Figure 7

A. Representative force myograph traces showing the effect of iberiotoxin and L-NAME on contraction force of intact carotid arteries with BaK. B. Mean data showing the effect of iberiotoxin on the contraction response to BaK after/before incubation with L-NAME. Data are expressed as means \pm SD $(n=10)$. Pvalue $<0.05$ was considered statistically significant. 


\section{Figure 8}

Western blot analysis showing the expression of caveolin-1 at 24-kDa, caveolin-3 at $18-\mathrm{kDa}$, Maxi-K channels at $9624 \mathrm{kDa}$, and a-actin at 42-kDa.

\section{Figure 9}

Proposed mechanisms of action of the NO on Maxi-K channels mediated hyperpolarization. 